International Journal of Advanced Research in Engineering and Technology (IJARET)

Volume 10, Issue 2, March-April 2019, pp. 612-623, Article ID: IJARET_10_02_058

Available online at http://iaeme.com/Home/issue/IJARET?Volume $=10 \& \overline{\mathrm{Issue}}=2$

ISSN Print: 0976-6480 and ISSN Online: 0976-6499

(C) IAEME Publication

\title{
EFFICIENCY OF ANTIMONOPOLY SERVICE IN THE EXERCISE OF PROCUREMENT CONTROL
}

\section{Mamedova N.A.}

Associate professor, Department of Information Systems Management and Programming, Plekhanov Russian University of Economics, Stremyanny lane, 36, Moscow, 117997, Russia

\section{Aleksandrova K.S.}

Postgraduate student of M.V. Lomonosov Moscow State University, Leninskie Gory 1, Moscow, 119899, Russia

\section{Larionov A.S.}

Global Clinical Sciences Department, Astellas Pharma Europe BV, Netherlands Mirai House, Sylviusweg 62, 2333 BE Leiden, Nederland

\begin{abstract}
In the article there was carried out the assessment of Federal Antimonopoly Service of Russian Federation (FAS Russia) activities based on approaches to efficiency evaluation of federal executive bodies according to process management criteria and indicators of results. The subject of the assessment is activity of FAS Russia and its territorial units in control in public and municipal procurement. Based on the report data of FAS Russia in 2016-2018 we have developed the set of criteria that was used for efficiency assessment. The results allow to expand analytical possibilities of efficiency assessment of the activity of FAS Russia for the purposes of program-target management. The assessment that was carried out with considering of proposed criteria is the optimal and sufficient source of primary data for assessing the effectiveness in future.

The value of results is confirmed by the development of methodological base for assessing of the federal executive bodies efficiency.
\end{abstract}

Keywords: efficiency of the federal executive bodies, efficiency assessment, contract system, control of procurement, FAS Russia, open data, process management criteria, and criteria of direct activities results.

Cite this Article: Mamedova N.A, Aleksandrova K.S and Larionov A.S, Efficiency of Antimonopoly Service in the Exercise of Procurement Control. International Journal of Advanced Research in Engineering and Technology, 10(2), 2019, pp. 612623.

http://iaeme.com/Home/issue/IJARET?Volume=10\&Issue $=2$ 


\section{INTRODUCTION}

Implementation of the program-targeted approach in management of budgets expenditures in Russia determines the direction of modern public administration development. Implementation of this approach, which was proposed in the Concept of Reforming the Budgetary Process in the Russian Federation in 2004-2006 (Resolution, 2004) as priorities, identified the definition of effectiveness and evaluation of the effectiveness of the management bodies. The traditional way of measuring effectiveness as the difference between achieved results and costs, cannot be applied to the evaluation of performance or effectiveness in the system of government.

Holding an assessment of effectiveness is possible only by determining and measuring the results of the activity of the valuation object. At the same time, the process of results identifying is associated with the impact of a number of factors hindering this (De Bruijn H, 2005) Socioeconomic significant results, as a rule, are achieved by the actions of the bodies involved in the management process. Therefore, highlighting the effectiveness of one of them is not a simple operation, in spite of a completely univocal division into the subjects of management and levels of government, the authorization and the definition of competence. In addition, there is a time lag between the management impact and the result, it can be more or less significant, as stated by (Zamecnik \& Rajnoha, 2015), and its duration is inversely proportional to the purity of the signal of management influence. That is, the longer the time lag between the action and the result is, the greater influence of indirect, conjugate and emerging factors affecting the final result. In this regard, the process of determining the effectiveness of managerial impact is complicated, since it is necessary to exclude the influence of other actions, which is not always possible, and take into account the error of the result.

\section{MATERIALS AND METHODS}

Modern approaches to assessing the effectiveness of government bodies are mostly focused on evaluating the effectiveness of management, which is characterized by a "product", an immediate result. Unlike the less popular approach for assessing social and economic efficiency, characterized by an "effect" or an end result, the evaluation of the "product" is quantifiable, which makes it possible to calculate the effectiveness of budget funds that was spent for achieving them. In this aspect, the evaluation of the performance of the FAS Russia is the optimal and sufficient source of primary data for assessing the effectiveness of its activities.

The most indicative for reflecting the effectiveness of the FAS Russia's activities are the criteria given in the report 'On the results of the activities of the bodies of the FAS Russia in monitoring compliance with the Russian Federation legislation in procurement' for 2017. The totality of these criteria, indicating their content and 'blind spots' of calculation, was used in the research, the subject of which is the assessment of the effectiveness of the FAS Russia. The methodological basis for the assessment was the methodology for evaluating the results of the quality management system (QMS), as well as the methodology for assessing the effectiveness of the Territorial Authorities (TA) of the FAS Russia, approved by Order No. 664/13 of the FAS Russia of 10.10.2013. Period of data analyzed: October 2016 - May 2018. The choice of the analysis period is explained by the availability of more complete information, both in the reports of the FAS Russia, and the data downloaded from the FTP-server of the Official site (www.zakupki.gov.ru). The effectiveness assessment was carried out in the following order:

1. Definition of particular criteria for the effectiveness of the FAS Russia.

2. Distribution of performance indicators of FAS Russia by private criteria.

3. Calculation of efficiency on the basis of calculation of values of particular criteria. 
4. Interpretation of the received calculation results.

Step 1. Defining particular criteria for the effectiveness of FAS Russia. At this stage, integrated criteria, reflecting a comprehensive line of activities and incorporating the main performance indicators of FAS Russia? are formed. The basis for the formation of the criteria was the reports on the results of the FAS Russia's activities, considered earlier in this section. The selected partial criteria are shown in Table 1. The criteria are defined in such way that they allow us to assess not only the quantitative indicators of the FAS Russia's activities, but also the qualitative ones, in particular, take into account the organizational performance and the quality of the agency's management system.

Table 1 Particular criteria for assessing the effectiveness of FAS Russia

\begin{tabular}{|c|c|c|c|}
\hline $\begin{array}{l}\text { № } \\
\text { п/ா }\end{array}$ & $\begin{array}{c}\text { Notation of partial } \\
\text { criteria }\end{array}$ & Assignment of partial criteria & $\begin{array}{l}\text { Weight of partial } \\
\text { criteria }(\beta)\end{array}$ \\
\hline 1. & $\mathrm{R}_{1}$ & $\begin{array}{l}\text { It characterizes the efficiency of handling complaints } \\
\text { against actions (inaction) of government customers }\end{array}$ & 0,13 \\
\hline 2. & $\mathrm{R}_{2}$ & $\begin{array}{c}\text { It characterizes the effectiveness of planned and } \\
\text { unscheduled inspections }\end{array}$ & 0,47 \\
\hline 3. & R3 & $\begin{array}{c}\text { It characterizes activities to maintain a register of } \\
\text { unfair suppliers (RUS) }\end{array}$ & 0,04 \\
\hline 4. & $\mathrm{R}_{4}$ & $\begin{array}{l}\text { Characterizes the regulatory and legal support for the } \\
\text { functioning of the system }\end{array}$ & 0,18 \\
\hline 5. & $\mathrm{R}_{5}$ & $\begin{array}{c}\text { Characterizes the effectiveness of the organizational } \\
\text { structure }\end{array}$ & 0,19 \\
\hline
\end{tabular}

Each particular criterion is assigned a weighting factor, determined on the basis of an expert evaluation of the influence of each criterion on the final result of efficiency. The degree of significance of each criterion was determined on the basis of the Saati scale for matrices of paired comparison (Saati T., 2012). In the role of experts, the TA FAS Russia officers in Moscow.

The consistency of the values was estimated by calculating the probability of an expert error. The maximum value of the error probability of experts was $2 \%$ when assessing the indicators of the R4 criterion. In other cases, the probability of error was excluded (since the error probability value was less than $0.5 \%$ ). To calculate each weight of a particular criterion, a matrix of paired comparisons was compiled (Table 2). Columns 2-6 of Table 2 show the assessors' evaluations of the criteria, based on the Saati scale.

Table 2 Calculation of weights of particular criteria

\begin{tabular}{|c|c|c|c|c|c|c|c|c|}
\hline Критерий & $\mathbf{R}_{\mathbf{1}}$ & $\mathbf{R}_{\mathbf{2}}$ & $\mathbf{R}_{\mathbf{3}}$ & $\mathbf{R}_{\mathbf{4}}$ & $\mathbf{R}_{\mathbf{5}}$ & $\begin{array}{c}\text { Multiplication } \\
\text { by rows (A) }\end{array}$ & $\begin{array}{c}\text { Vector of } \\
\text { preferences } \\
(\overline{\boldsymbol{n}})\end{array}$ & $\begin{array}{c}\text { Weight of } \\
\text { criterion } \\
(\mathbf{V})\end{array}$ \\
\hline 1 & 2 & 3 & 4 & 5 & 6 & 7 & 8 & 9 \\
\hline $\mathrm{R}_{1}$ & 1 & $1 / 3$ & 5 & 1 & $1 / 3$ & 0,56 & 0,89 & 0,13 \\
\hline $\mathrm{R}_{2}$ & 3 & 1 & 7 & 3 & 5 & 315,0 & 3,16 & 0,47 \\
\hline $\mathrm{R}_{3}$ & $1 / 5$ & $1 / 7$ & 1 & $1 / 7$ & $1 / 5$ & 0,0 & 0,24 & 0,04 \\
\hline $\mathrm{R}_{4}$ & 1 & $1 / 3$ & 7 & 1 & 1 & 2,33 & 1,19 & 0,18 \\
\hline $\mathrm{R}_{5}$ & 3 & $1 / 5$ & 5 & 1 & 1 & 3,00 & 1,25 & 0,19 \\
\hline Сумма & 8,2 & 2,0 & 25 & 6,2 & 7,5 & 320,9 & 6,7 & 1,0 \\
\hline
\end{tabular}

The vector of preferences, which allows to determine the degree of influence of each indicator and is calculated by the formula: 


$$
\bar{n}=\sqrt[N]{A}
$$

$N$ - number of criteria compared;

$A$-multiplication of expert judgments by line.

In this case, the value of the preference vector for the criterion $\mathrm{R} 1$ is:

$$
\bar{n}=\sqrt[5]{1 * \frac{1}{3} * 5 * 1 * \frac{1}{3}}=0,889
$$

The determination of the weight of each criterion makes it possible to determine the degree of influence of the criterion on the overall effectiveness evaluation.

The weight of the criterion $\mathrm{V}$ is calculated as the ratio of the value of the preference vector to the total value of the preference vectors. For example, the weight of the criterion R1 will be:

$$
R_{1}=\frac{\bar{n}_{i}}{\sum_{1}^{n} \bar{n}}=\frac{\bar{n}_{1}}{\sum_{1}^{5} \bar{n}}=\frac{0,889}{6,7}=0,13
$$

$\sum_{1}^{n} \bar{n}$ - the sum of the values of the criteria preference vectors;

$\bar{n}_{i}$ - the value of the preference vector for a particular criterion.

This method allows to obtain smoothed values, excluding critical points, which can distort the final result.

Step 2. Distribution of performance indicators of FAS Russia for specific particular criteria. At this stage, it is necessary to compare each particular criterion with the corresponding indicator, which most fully reflects the essence of the criterion. We selected indicators that are measurable quantitatively and qualitatively (Mamedova, Urintsov, \& Savrukov, 2017), as well as those about which the information is most fully represented (Dik, Urintsov, Odintsov, \& Churikanova, 2014; Ogiela \& Ogiela, 2015). The results of comparison of the indicators with particular criteria are given in Table 3 . For each indicator of the particular criterion, the weighting coefficient was also determined similarly to the algorithm presented in

\begin{tabular}{|c|c|c|c|c|}
\hline № & $\begin{array}{c}\text { Notation } \\
\text { of } \\
\text { partial } \\
\text { criteria }\end{array}$ & Assignment of partial criteria & $\begin{array}{l}\text { Value of } \\
\text { partial } \\
\text { criteria }\end{array}$ & $\begin{array}{l}\text { Weight } \\
\text { of partial } \\
\text { criteria }\end{array}$ \\
\hline \multirow{5}{*}{ 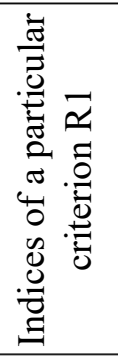 } & $\mathrm{A}_{1}$ & The share of reviewed complaints from bidders & 0,58 & 0,18 \\
\hline & $\mathrm{A}_{2}$ & The share of complaints found to be justified & 0,24 & 0,20 \\
\hline & $\mathrm{A}_{3}$ & The share of complaints recognized as unfounded & 0,34 & 0,06 \\
\hline & $\mathrm{A}_{4}$ & $\begin{array}{l}\text { The share of successful appeals of decisions in court (in } \% \\
\text { of the total number of decisions taken) }\end{array}$ & 0,03 & 0,30 \\
\hline & $\mathrm{A}_{5}$ & $\begin{array}{l}\text { Prescriptions were given (in } \% \text { of the total number of } \\
\text { decisions taken on the existence of a violation) }\end{array}$ & 0,03 & 0,26 \\
\hline \multirow{4}{*}{ 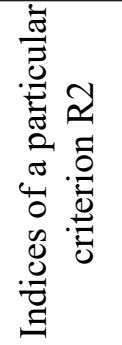 } & $\mathrm{P}_{1}$ & $\begin{array}{l}\text { The share of planned inspections conducted as a } \\
\text { percentage of the total number of inspections }\end{array}$ & 0,03 & 0,25 \\
\hline & $\mathrm{P}_{2}$ & $\begin{array}{l}\text { The share of conducted unscheduled inspections as a } \\
\text { percentage of the total number of inspections }\end{array}$ & 0,97 & 0,08 \\
\hline & $\mathrm{P}_{3}$ & The share of audits whose results are declared invalid & $-0,01$ & 0,14 \\
\hline & $\mathrm{P}_{4}$ & $\begin{array}{l}\text { The share of offenses identified following the results of } \\
\text { inspections }\end{array}$ & 0,74 & 0,20 \\
\hline
\end{tabular}
Table 2.

Table 3 Indicators for calculating criteria R1-R5 
Efficiency of Antimonopoly Service in the Exercise of Procurement Control

\begin{tabular}{|c|c|c|c|c|}
\hline № & $\begin{array}{c}\text { Notation } \\
\text { of } \\
\text { partial } \\
\text { criteria } \\
\end{array}$ & Assignment of partial criteria & $\begin{array}{l}\text { Value of } \\
\text { partial } \\
\text { criteria }\end{array}$ & $\begin{array}{l}\text { Weight } \\
\text { of partial } \\
\text { criteria }\end{array}$ \\
\hline & $\mathrm{P}_{5}$ & $\begin{array}{l}\text { The share of inspections, which resulted in the initiation } \\
\text { of cases on administrative offenses }\end{array}$ & 0,27 & 0,10 \\
\hline & $\mathrm{P}_{6}$ & $\begin{array}{l}\text { The share of the amount of collected administrative fines } \\
\text { to the total amount of administrative fines imposed }\end{array}$ & 0,48 & 0,15 \\
\hline & $\mathrm{P}_{7}$ & $\begin{array}{l}\text { The share of offenses related to non-compliance with the } \\
\text { requirements identified during inspections }\end{array}$ & 0,28 & 0,09 \\
\hline \multirow{2}{*}{ 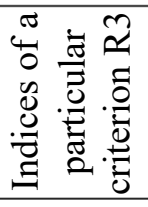 } & U1 & $\begin{array}{c}\text { The share of suppliers entered in the RUS, to the total } \\
\text { number of contract evaders }\end{array}$ & 0,69 & 0,63 \\
\hline & $\mathrm{U} 2$ & $\begin{array}{l}\text { The share of suppliers entered in the RUS, to the number } \\
\text { of canceled contracts on the initiative of the customer }\end{array}$ & 0,31 & 0,37 \\
\hline \multirow{4}{*}{ 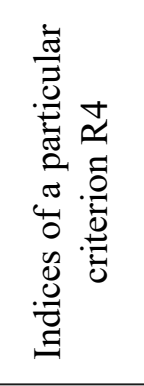 } & $\mathrm{N}_{1}$ & $\begin{array}{c}\text { Presence of normative acts defining typical forms of } \\
\text { outgoing documents }\end{array}$ & 0,3 & 0,32 \\
\hline & $\mathrm{N}_{2}$ & $\begin{array}{l}\text { Presence of normative and legal acts determining the } \\
\text { procedure for exercising control }\end{array}$ & 0,5 & 0,23 \\
\hline & $\mathrm{N}_{3}$ & $\begin{array}{l}\text { Providing reports on the results of control (completeness, } \\
\text { degree of thoroughness, interpretation of the results) }\end{array}$ & 0,3 & 0,19 \\
\hline & $\mathrm{N}_{4}$ & $\begin{array}{l}\text { Self-assessment of the effectiveness of the activity (the } \\
\text { availability of the methodology and its application) }\end{array}$ & 0,3 & 0,27 \\
\hline \multirow{4}{*}{ 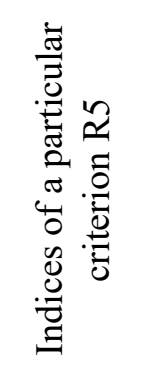 } & $\mathrm{O}_{1}$ & $\begin{array}{c}\text { The share of employees exercising control in public } \\
\text { procurement }\end{array}$ & 0,18 & 0,25 \\
\hline & $\mathrm{O}_{2}$ & $\begin{array}{l}\text { The share of employees who underwent further training } \\
\text { (training) in public procurement }\end{array}$ & 0,14 & 0,13 \\
\hline & $\mathrm{O}_{3}$ & $\begin{array}{l}\text { The average workload per employee (the ratio of the } \\
\text { number of functions to the number of employees) }\end{array}$ & $-1,04$ & 0,23 \\
\hline & $\mathrm{O}_{4}$ & $\begin{array}{l}\text { The share of the TA FAS Russia, which assesses the } \\
\text { performance of employees }\end{array}$ & 0,16 & 0,38 \\
\hline
\end{tabular}

Step 3. Calculation of efficiency on the basis of calculation of values of particular criteria. Calculation of the criterion R1 is carried out according to the following formula:

$$
R_{1}=\frac{\sum_{i=1}^{5} \gamma_{i^{*}} A_{i}}{\sum_{1}^{5} \gamma_{i}},
$$

$A_{i}$ - value of the analyzed indicator,

$\gamma_{i}-$ weight of the indicator.

According to the calculation,

$$
\begin{gathered}
R_{1}=\frac{0,18 * 0,58+0,2 * 0,24+0,06 * 0,34+0,3 * 0,03+0,26 * 0,03}{0,18+0,2+0,06+0,3+0,26}=\frac{0,188}{1} \\
R_{1}=0,19 \text { or } 19 \%
\end{gathered}
$$

Similarly, R2-R5 is calculated. The result is interpreted as follows: the effectiveness of the FAS Russia's activities in the implementation of the function to review the complaints of the participants in procurement for actions (inaction) of government customers is $19 \%$, which can be qualified as "low efficiency".

Let's make some justification for the calculation and interpretation of the selected indicators. Table 3 shows the indicators that most fully reflect the essence of the criterion of 
"effectiveness of planned and unscheduled inspections" (R2). The indicators are selected in such way that they allow comparing the control process (conducting inspections) with its effectiveness (the proportion of violations detected, penalties collected, etc.). Indicator P1 is taken with a negative value to achieve uniformity of the system of indicators, since the influence of this indicator on the overall efficiency is inversely proportional, i.e. the lower it is, the higher the efficiency of FAS Russia in the end.

As a result of calculations (similar to the calculation of $\mathrm{R} 1$ ), it was found that $\mathrm{R} 2=0.35$. Thus, the effectiveness of FAS Russia's activities in the implementation of audits is $35 \%$. This indicates a lack of high quality of work in the conduct of inspections, but on the whole the result cannot be called ineffective. This result was negatively affected by the low share of planned inspections, the weight of which in the general cut of all criteria is $25 \%$. It turns out that the indicator that has the greatest impact on the overall effectiveness of the FAS Russia, in practice, is the smaller part of the number of inspections conducted. Accordingly, the result obtained is a practical confirmation of the hypothesis advanced earlier on the insufficient number of planned inspections.

The justification of calculating and interpreting according to the efficiency criterion in the FAS Russia's implementation of the function of keeping the register of unfair suppliers (R3) is as follows. Only two indicators were identified (these indicators are used by FAS Russia, other indicators are not taken into account), the weights of which are not so significant, but the effect on the overall effectiveness of these indicators really do. The criterion R3 $=0,55$ or $55 \%$. To achieve higher efficiency results, indicators that are associated with the quality of FAS Russia's performance are of particular importance. Primarily, this is the provision of regulatory and legal acts, their application, as well as independent monitoring by the state body of the results of its activities by self-examination.

Indicators reflecting the effectiveness of regulatory support for the functioning of the FAS Russia (R4) were calculated on the basis of a scoring methodology. Each indicator was assigned a maximum of 0.5 points (the final maximum score is 2 points). The evaluation was based on the analysis of data in the analytical reports of the FAS Russia, as well as on the basis of expert assessments of the employees of the Moscow OFAS. The experts of the Moscow TA FAS Russia also acted as experts. Weights of the criteria were also determined on the basis of the Saati scale. As a result of the calculation, the result by the criterion was: R4 $=0.34(34 \%)$.

Thus, it is possible to characterize the activities of FAS Russia in providing normative and legal support for the implementation of the state function to control public procurement as "insufficiently effective". This result was influenced by the inadequate quality of reporting and the lack of up-to-date data on the agency's website, as well as the lack of an approved methodology for assessing the effectiveness of activities in the context of monitoring public procurement.

When assessing the effectiveness of the FAS Russia, the organizational aspect that identifies the way in which the management system operates within the organization is also significant. In the study, the criterion R5 reflects the effectiveness of the organizational structure of the FAS Russia. The result of the criterion calculation is: R5 $=-0.19$. Such a low result was a consequence of the influence of a combination of factors. First, during the analysis of load distribution by territorial bodies, it was found that the main part of workload falls on 34 territorial bodies of all. Moreover, when analyzing the number of civil servants, it was established that the total number of labor functions performed in the field of control over public procurement amounted to 187,083 units. At the same time, the number of employees employed in the process of performing these functions is 571 people. 
The average workload per employee is 327.6 functions for the second half of the year in 2017. Given the vacant positions, the assumption of such overloads in the work of the staff indicates the inefficiency of the organizational structure and the uneven distribution of workload among employees. This, in particular, can explain the untimely publication of information on the Official site, the delay in the issuance of decisions to the members of the complaints committee, etc. The $\mathrm{O} 3$ indicator is a variable indicator, that is, if one function per employee is the optimal value (taking into account the time spent for the function), the values above or below the unit are subtracted from the overall result of the R5 criterion. It is important to understand that one function (for example, review of complaints) includes several subfunctions (notification of consideration of a complaint, participation in a commission meeting, preparation of a decision, notification of a decision).

In addition to these factors, the lack of a system of self-examination of the effectiveness of FAS Russia's activities in exercising control over public procurement also had a negative impact on the value of R5. Within the framework of the study, the fact that the $\mathrm{O} 4$ index has the largest weight and the smallest value, led to a general decrease in the value of the R5 criterion.

Table 4 shows the final value of each criterion R1 -R5, as well as the multiplication of the obtained values and their weights.

Table 4 Final values of particular performance criteria

\begin{tabular}{|c|c|c|c|}
\hline Criterion & $\begin{array}{c}\text { Value } \\
(\boldsymbol{\alpha})\end{array}$ & $\begin{array}{c}\text { Weight } \\
(\boldsymbol{\beta})\end{array}$ & $\boldsymbol{\alpha} * \boldsymbol{\beta}$ \\
\hline $\mathrm{R} 1$ & 0,188 & 0,13 & 0,025 \\
\hline $\mathrm{R} 2$ & 0,350 & 0,47 & 0,164 \\
\hline $\mathrm{R} 3$ & 0,551 & 0,04 & 0,019 \\
\hline $\mathrm{R} 4$ & 0,345 & 0,18 & 0,060 \\
\hline $\mathrm{R} 5$ & $-0,190$ & 0,19 & $-0,035$ \\
\hline Итого: & 1,244 & 1,00 & 0,23 \\
\hline
\end{tabular}

Resource: Compiled by the authors

Thus, the final assessment of the effectiveness of FAS Russia in exercising control over public procurement is:

$$
\begin{gathered}
R=\frac{\sum_{i=1}^{5} \alpha_{i} * \beta_{i}}{\sum_{1}^{5} \beta_{i}} * 100 \%, \\
R=23 \%
\end{gathered}
$$

Step 4. Interpretation of the received calculation results. Based on the scale of interpretation of the calculation results given in Table 5, we can conclude that the level of effectiveness of the FAS Russia activities for the period October 2016 - May 2018 is "unacceptable". However, it is necessary to take into account the subjectivity of expert assessments, which could affect the weights of the indicators, as well as the irrelevance or incorrectness of data published in the public domain. However, there were also reasons for such low results. 
Table 5 Interpretation of the resulting summary value of effectiveness

\begin{tabular}{|c|c|}
\hline The value of the efficiency, $\%$ & Performance evaluation meaning \\
\hline $\mathrm{R}<50$ & unsatisfactory \\
\hline $50 \leq \mathrm{R}<60$ & ineffective \\
\hline $60 \leq \mathrm{R}<80$ & moderately effective \\
\hline $\mathrm{R} \geq 80$ & effective \\
\hline
\end{tabular}

\section{RESULTS OF THE STUDY}

All selected indicators comprehensively reflect the activities of FAS Russia. It must be understood that, nevertheless, the problems of organizing the system of control over public procurement and the problems of its functioning are not fictitious, but represent a real threat to the effectiveness of public procurement control. Highly qualified specialists, a competently built algorithm for interaction between employees who perform functions to control public procurement, a uniform distribution of employment of civil servants, as well as an orientation toward identifying the causes of violations - all this in a complex will significantly improve the effectiveness of FAS Russia.

The results of the research made it possible to identify the most problematic and vulnerable aspects of the effectiveness of public procurement control carried out by the FAS Russia. The public procurement control system provided by the law on the contract system is complex and involves the involvement of several government bodies. The study of the effectiveness of the FAS Russia allows you to compare the results with the results of other departments. Such a comparison will make it possible at early stages to identify the systemic nature of the problem and eliminate it through joint action.

\section{FINDINGS}

Recommendations on increasing the effectiveness of FAS Russia's activities in the field of control over public procurement.

Since the objectives of the research were to obtain substantiated results of generalizing the practice of FAS Russia for a certain period of time, in identifying and interpreting the performance indicators of its activities and performing efficiency assessments based on the author's methodology, the following can be noted as recommendations:

1. Creating an on-line form for complaint. During the analysis of the FAS Russia's performance indicators with complaints, it was found that a significant number of complaints are returned on formal data (the applicant's absence of indication of e-mail, telephone, etc.). In the electronic form, it is suggested to set mandatory fields that the applicant will not miss, given the settings. Further, now the applicant also attaches the complaint text in electronic format. However, in the long term, if you consider the electronic form of filing a complaint, you should implement the function of tracking the status of a complaint in the personal account of the applicant. Input of data via on-line form will allow the applicant to promptly enter the necessary information according to the specified criteria, which will allow forming a full interactive complaint database, on the basis of which it is possible to analyze the most popular objects of appeal, to display TOP customers for the largest / smallest number of complaints,

As a result, the complaint process will be improved. The appeal form will be on the Official site (and, accordingly, integrated with all its sections), by the notification number it will be possible to identify the purchase. Further on the selected subject of the complaint, whose actions are appealed, the name and other information regarding the subject of the complaint, as 
well as all data on the merits of the complaint entered by the applicant, are loaded into a special database.

This will reduce the number of complaints returned on formal grounds, ensure transparency and openness of the complaint process, will help to develop approaches to comprehensive independent analysis of data. The complexity of the implementation of this tool lies in the limited current capabilities of the FAS site of the Russian Federation and the Official site, as well as the fact that the applicant will in any case have to confirm the submitted complaint with an electronic digital signature.

2. Automation of notifications of the subjects of the complaint about the consideration of the complaint on the merits (call on the commission). During the analysis of the texts of calls of the subjects of complaints to the commission for review of the complaint, it was established that this type of notification is not completely unified for all TA FAS Russia.

To automate the organization of the process of notifying the subjects of complaints (participants in procurement and customers) to consider the complaint on the merits, it is proposed to create an automatically completed form that will be integrated with the electronic document management system of the Federal Antimonopoly Service of Russia (OpenOffice) and the Official Website. This is possible, since the notice indicates all the necessary information regarding the subject of procurement, the customer, etc. A unified form (pattern) can be a notification, the fragments of which can be filled automatically. Identification of the data will occur by the purchase number. The remaining parts of the text of the notice remain unchanged, since they contain the necessary references to articles of the law on the contract system.

In the database of registration of incoming documents, the procurement number in FAS Russia is entered, the subject of the complaint whose actions are being appealed and who is the applicant - all these data can be "pulled" from the FAS Russia database into the automated template when preparing the notification. It is proposed for each FAS Russia to prepare such notification templates with the appropriate address and contacts of the FAS Russia where the complaint will be examined on the merits.

In this regard, it is proposed to revise the requirements of Federal Law No. 44-FZ on the written notification of the applicants about the return of the complaint. If all information is fully reflected on the Official Website, in the event that the complaint does not comply with the established requirements, there will be no need to send a written notice to the applicants.

3. Analysis of work load of the FAS Russia. It is advisable to carry out an assessment of the compliance of the work load with the number of workplaces of employees engaged in the control of public procurement. It is important to understand that there is a direct link between the quality of review, for example, of decisions made on the basis of complaints, and the number of complaints considered by one staff member. This proposal should be considered a separate area for conducting research in the context of optimizing functions and organizing the activities of the FAS Russia.

4. Improving the effectiveness of public procurement control. On the overall assessment of the effectiveness of the FAS Russia had a significant effect on the ratio of planned and unscheduled inspections (taking into account the accepted weight values). It was established that the FAS Russia in its practical activities basically does not prevent the emergence of offenses, but suppresses them even after the occurrence.

In this regard, as a recommendation to improve the effectiveness of public procurement control, we would like to sign out an increase in the number of planned inspections. Moreover, it is recommended that the audit plan include those customers who received a greater number 
of justified complaints in the previous period. Undoubtedly, the decision-making within the framework of this proposal should take into account the aspect of load sharing between employees in the total amount of jobs.

When creating a database in assessing the effectiveness of the FAS Russia on the basis of data from the ftp-server of the Official site it became possible to form an array of data on complaints in the context of customers. This allowed to form a kind of rating of unscrupulous customers. In the future, this rating can serve as a basis for planning the conduct of inspections of planned inspections in the FAS Russia.

Our proposal is as follows: FAS Russia will by the end of the year unload the rating of customers that received the most complaints, and also indicate how many complaints for each customer were found to be justified. Then the top unscrupulous customers (for example, TOP10), authorized bodies, procurement commissions, etc. are selected. Also, in addition to the audit plan, we propose to include customers who did not qualify for the TOP-100, but for which there were no planned inspections for the last calendar year.

In accordance with paragraph 13 of Art. 99 of Federal Law No. 44-FZ, scheduled inspections are carried out for customers, authorized bodies, contract service, contract manager, operators of the electronic platform, etc. not more than once in 6 months. However, we consider it expedient to include the first 10 customers in the TOP-100 in the audit plan again, until a noticeable reduction in the detected offenses is achieved. Accordingly, it is necessary to make the appropriate amendments to paragraph 13. Art. 99, providing for the possibility of repeated inspections of dishonest customers for certain reasons.

We also consider that it is necessary to place a list of such customers openly on the official website, or on the website of the FAS Russia. Perhaps the psychological effect of the publicity of such information on the activities of government customers on procurement management. And it will influence the customer's choice of competitive procedures in which they plan to participate.

The increase in the share of planned inspections in the total number of inspections conducted by FAS Russia, in conjunction with the introduction of the proposed rating, will definitely have a positive effect on the growth of the value of the efficiency criterion R2 (the effectiveness of planned and unscheduled inspections). As it is expected that the application of the developed recommendations will also reduce the number of offenses, this will indicate an increase in the overall assessment of the effectiveness of FAS Russia.

5. Proposals for the content of reports and analytical materials. The next proposal to improve the effectiveness of public procurement control, implemented by FAS Russia, is the formation of a strict system of reporting and monitoring the activities of FAS Russia in the context of self-examination. We proceed from the premise that the provision of up-to-date reporting, the disclosure of key performance indicators of FAS Russia with an open method of calculation and interpretation contribute to an increase in the openness and transparency of the procurement control system. In this regard, it is proposed to keep records not only at the end of the year, but also half-yearly. In the semi-annual reports, the following information should be reflected:

- number of complaints considered (including: justified, unreasonable, returned and withdrawn);

- number of issued prescriptions;

- number of executed orders;

- number of administrative offenses;

- the number of inspections (planned and unplanned) and the results of their audits. 
Providing even such a compressed report for half a year will allow to identify those customers who received a greater number of complaints for the quarter, and also to monitor how many orders issued by FAS Russia were not executed. Accordingly, the first report should be published by June 30, the second by December 30, and by March 30, an extended report on the results of the previous year's work should be provided.

Moreover, in addition to assessing the effectiveness of certain functions, an important point is the evaluation of civil servants performing functions to control public procurement. Currently, there is no assessment of the effectiveness of the FAS Russia staff. As criteria for assessing the effectiveness of civil servants, the following can be taken into account:

- the number of violations of the timing of decision-making;

- the number of cases of not posting information about the complaint;

- share of decisions taken;

- the share of inspections conducted upon the execution of the issued order, etc.

Carrying out such an assessment will make it possible to compare the results of employees in similar positions, compare and distribute the workload, and possibly revise the distribution of some functions. Moreover, assessing the performance of employees will identify inefficient employees. High employee performance ratings can be used as a basis for planning bonuses and additional rewards for efficient employees.

Thus, in this article, an assessment was made of the effectiveness of FAS Russia's control in public procurement, identified the main problems associated with the implementation of this control, and developed a set of recommendations to improve the effectiveness of FAS Russia activity.

\section{REFERENCES}

[1] Saati T. (2012). Analysis of hierarchies Saati T. Problems of science and education, 2, URL: http://www.science-education.ru/102-6009

[2] Prasanna Kumar, Dr. Mervin Herbert and Dr. Srikanth Rao (2015), Genetic Algorithm Approach for Analysis of Multi Item Multi Period Procurement Lot Sizing Problem. International Journal of Management, 6(12), 2015, pp. 50-58

[3] De Bruijn H. (2005). Governance on Results in the Public Sector: Per. with English. H. De Bruijn. Moscow: Institute for Complex Strategic Studies

[4] Zahraa Jabbar Hussein and Chasib Hasan abboodi (2018), Selecting Decision Support System Technique to Choose Best Supplier in Procurement of Iraqi Public Sector, International Journal of Civil Engineering and Technology, 9(5), 2018, pp. 144-154.

[5] Dik, V. V., Urintsov, A. I., Odintsov, B. Y., \& Churikanova, O. Y. (2014). Decision support methods in balanced scorecard. Naukovyi Visnyk Natsionalnoho Hirnychoho Universytetu (4), 120-126.

[6] Mamedova N.A, Savrukov A.N, Savrukov N.T and Kozlovskaya E.A (2018), Determinants of Cartel Collusion of Participants in Public Procurement, International Journal of Mechanical Engineering and Technology, 9(11), 2018, pp. 1183-1187

[7] Mamedova, N. A., Urintsov, A. I., \& Savrukov, A. N. (2017). Features of the architecture of information resources in the field of public procurement (Russian contract system). International Journal of Applied Engineering Research, 12(16), 5976-5983.

[8] Ogiela, L., \& Ogiela, M. R. (2015). Comparison of Cognitive Information Systems Supporting Management Tasks. 2015 International Conference on Intelligent Networking and Collaborative Systems Ieee Incos 2015, 49-56. doi:10.1109/INCoS.2015.63

[9] Payel Roy and Dr. Pradip Kumar Samanta (2017), Analysis of Non-Performing Assets in Public Sector Banks of India. International Journal of Management, 8(1), 2017, pp. 21-29. 
[10] Resolution of the Government of the Russian Federation of 22.05.2004 No. 249 "On Measures to Improve the Effectiveness of Budget Expenditures" (together with the "Concept of Reforming the Budgetary Process in the Russian Federation in 2004-2006", "Plan of Measures to Implement the Concept of the Budget Process Reform in the Russian Federation in 2004 - 2006 ")

[11] Joseph N. Mkilania (2016), Factors Affecting Best Maintenance Practice In Tanzania Public Sector. International Journal of Mechanical Engineering and Technology, 7(3), 2016, pp. 139-149.

[12] Zamecnik, R., \& Rajnoha, R. (2015). Strategic business performance management on the base of controlling and managerial information support. 4th World Conference on Business, Economics and Management (Wcbem-2015), 26, 769-776. doi:10.1016/s22125671(15)00843-6 